\title{
GEOCHEMISTRY
}

\section{El Niño Events Recorded by Stalagmite Carbon Isotopes}

\section{Amy Frappier, ${ }^{1 *}$ Dork Sahagian, ${ }^{1}$ Luis A. González, ${ }^{2,3}$ Scott J. Carpenter ${ }^{2,3}$}

The El Niño/Southern Oscillation (ENSO) system is a prominent component of interannual climate variability, and the Southern Oscillation Index (SOI) is a primary measure of the state of the ENSO system (1). Here, we present evidence that ENSO-related changes in the terrestrial carbon cycle can be recorded by stalagmites, thus providing a proxy for past El Niño events. Our analysis of a stalagmite from Belize reveals a strong correlation between the SOI and carbon isotope ratios ( $\delta^{13} \mathrm{C}$ values), even though the site experiences no discernible local weather effects that are correlated with the SOI. $\delta^{13} \mathrm{C}$ values of this stalagmite must reflect changes in the overlying rainforest ecosystem's carbon budget that are sensitive to subtle modifications of local weather related to ENSO.

Using high-resolution microsampling techniques for stable isotope analysis $(2,3)(\sim 1300$ samples at $20 \mu \mathrm{m}$ increments producing weekly to monthly temporal resolution), we have discovered large $[-13.3$ to -2.2 per mil (\%) ], rapid ( $\sim 7 \%$ in $\sim 6$ months) fluctuations in speleothem $\delta^{13} \mathrm{C}$ values at interannual to subseasonal time scales. Our analysis of a rapidly growing calcite stalagmite (ATM7) from the cave Actun Tunichil Muknal in central Belize indicates a remarkably strong correlation between $\delta^{13} \mathrm{C}$ values and recent El Niño events (Fig. 1). Discovery of this relation is puzzling in light of the absence of significant weather anomalies during recent El Niño and La Niña intervals for this area. Analysis of meteorological data does not show any statistically significant correlations between the SOI and local meteorological observations (supporting online text). El Niño events apparently trigger a response of the carbon isotope system in this area such that a coherent El Niño signal is derived from indiscernible local weather fluctuations. Ecosystem sensitivity to weak climate signals has been modeled for marine ecosystems in the North Atlantic (4).

ATM7 was actively growing at the time of collection (January 2001) and contains visible band pairs that are distinguished by variations in color, fluid inclusion density, stable oxygen isotope ratios, and trace element composition. Results of ${ }^{137} \mathrm{Cs}$ dating support our interpretation of visible band pairs as annual couplets. Counting backward through the layers from the actively growing stalagmite surface, the base of each annual couplet was assigned a March date (average onset of the dry season) for the appropriate year. The time required for meteoric water (car-

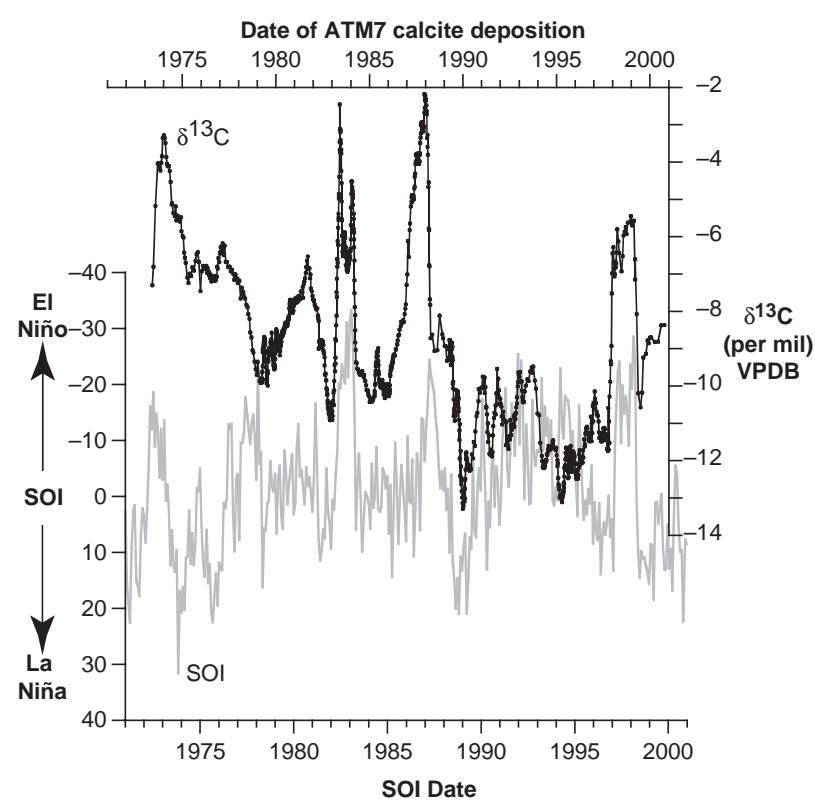

Fig. 1. ATM7 carbon isotope record and Southern Oscillation Index (SOI). Stalagmite $\delta^{13} \mathrm{C}$ values (black) are depicted with the SOI (gray, inverted). The time scales and associated curves are offset, reflecting the time lag between SOI and ATM7 calcite deposition. Strong El Niño events (1987-88, 1997-98, and 1982-83) and lower amplitude events (early 1990s, 1979-81, and 1970s) are readily apparent. ATM7 was collected in January 2001 from Actun Tunichil Muknal in central Belize. Temporal resolution is $\sim$ weekly to monthTunichil Muknal in central Belize. Temporal resolution is $\sim$ we
ly. $\delta^{13} \mathrm{C}$ data are reported in per mil (\%o) relative to V-PDB.

rying dissolved $\mathrm{CO}_{2}$ ) to percolate through the soil and bedrock to the cave is estimated at 3 to 10 months for ATM7.

A number of mechanisms may be responsible for the large variation observed in stalagmite $\delta^{13} \mathrm{C}$ values (Fig. 1). Under tropical rainforest canopies, the $\delta^{13} \mathrm{C}$ values of $\mathrm{CO}_{2}$ can be very low $(<-33 \%)$ because of recycling of respired $\mathrm{CO}_{2}(5)$. Changes in soil respiration rates (or soil $p \mathrm{CO}_{2}$ ) can also modify the $\delta^{13} \mathrm{C}$ value of soil $\mathrm{CO}_{2}(6)$. Changes in the $\mathrm{pH}$ of drip water, contribution of organic versus dissolved limestone bedrock carbon, regional isotopic composition of atmospheric $\mathrm{CO}_{2}(7)$, and degassing rates of drip water within the cave are unlikely to be important factors because even the maximum magnitudes of these effects are insufficient to produce the observed $\delta^{13} \mathrm{C}$ variations. We suggest that variation in ATM7 $\delta^{13} \mathrm{C}$ values may arise primarily from changes in local rates of soil respiration and ecosystem $\mathrm{CO}_{2}$ recycling; however, the relative importance of various processes (e.g., autotrophic versus heterotrophic respiration and degree of soil-atmosphere $\mathrm{CO}_{2}$ exchange) currently remains unconstrained.

ENSO-driven changes in terrestrial ecosystem carbon cycle dynamics from regions without obvious ENSO teleconnections may be an important component of seasonal to decadal changes in global $\mathrm{CO}_{2}$ fluxes. Our findings indicate that some ecological systems are capable of magnifying the amplitude of weak or distributed local climate signals such as ENSO. This work further suggests that ENSO affects a much larger area than just where fluctuations in weather patterns are discernible. This stalagmite isotope record provides not only an El Niño proxy, but also records significant and measurable variation (at internannual and shorter time scales) in the carbon cycle of tropical rainforest ecosystems on subannual time scales that merits further examination.

\section{References and Notes}

1. A. J. Troup, Q. J. R. Meteorol. Soc. 91, 490 (1965).

2. S. Carpenter, Geol. Soc. Am. Abstr. Program 28, 360 (1996).

3. Materials and methods are available as supporting material on Science Online.

4. A. Taylor, J. Allen, P. Clark, Nature 416, 629 (2002).

5. M. S. L. Broadmeadow, H. Griffiths, in Stable Isotopes and Plant Carbon-Water Relations, J. R. H. Ehleringer, A. E. Hall, G. D. Farquhar, Eds. (Academic Press, New York, 1993), pp. 109-129.

6. T. E. Cerling, Y. Wang, J. Quade, Nature 361, 344 (1993).

7. P. P. Bousquet, P. Ciais, C. Le Quere, P. Friedlingstein P. P. Tans, Science 290, 1342 (2000)

8. We thank J. Dibb for dating, J. Awe and the Belize Department of Archaeology for permits, the Belize Meteorological Service for weather data, B. Frappier for field and technical support, and A. Juan of Mayawalk Tours for field logistics. This work was supported by NSF grant ATM-0081293, the Environmental Protection Agency STAR Fellowship Program the N.H. Space Grant Consortium, and the lola Hubbard Climate Change Endowment.

Supporting Online Material

www.sciencemag.org/cgi/content/full/298/5593/565/

DC1

Materials and Methods

Supporting Text

Table S1

${ }^{1}$ Institute for the Study of Earth, Oceans and Space; Climate Change Research Center; and Department of Earth Sciences, University of New Hampshire, Durham, NH 03824, USA. ${ }^{2}$ Department of Geoscience and ${ }^{3}$ Center for Global and Regional Environmental Research, University of lowa, lowa City, IA 52242, USA.

*To whom correspondence should be addressed. Email: a.frappier@unh.edu 